\title{
A PEREGRINAÇÃO EM BUSCA DA CASA
}

\section{PILGRIMAGE IN SEARCH OF THE HOUSE}

\section{Bruno da Silva da Silveira \\ Graduando em Psicologia UNESC, Integrante do \\ GIPMAUR - UNESC. Email: bruno-}

silvasilveira@unesc.net

Maicol Oliveira Brognoli

Psicólogo, Integrante do GIPMAUR - UNESC. Email: maicolbrognoligmail.com

Teresinha Maria Gonçalves

Docente do Programa de Pós-Graduação em Ciências Ambientais (Mestrado e Doutorado) - UNESC, Coordenadora do GIPMAUR - UNESC. Email: teresaakira@gmail.com

\section{RESUMO}

Este artigo resulta de uma pesquisa sobre a questão da moradia em uma unidade de conjunto habitacional do programa "Minha Casa Minha Vida" da cidade de Criciúma/SC. A reflexão segue na linha da Psicologia Ambiental, da Filosofia e da Geografia Cultural. O objetivo foi entender o processo de busca da casa por meio do conceito de peregrinação, identificado durante as entrevistas. A amostra da pesquisa foi composta por 54 moradores. A pesquisa se deu pela abordagem qualitativa nas modalidades exploratória e explicativa no sentido de entender a dinâmica da busca pela casa própria. A pesquisa identificou que, na história de vida das pessoas, esteve presente um processo de peregrinação e a busca pelo lugar essencial entendido como casa, marcado por grandes sofrimentos e expectativas. Os instrumentos de coleta de dados foram a observação sistemática e entrevistas semiestruturadas. Os achados da pesquisa foram: a casa do conjunto se caracteriza pelo conceito de casa biológica, o conjunto compõe a parte segregada da cidade, a maioria dos moradores estão em situação de trabalho precário, não há vida coletiva e as pessoas demonstraram descontentamento e falta de apropriação pela casa em que moram. Os peregrinos, em busca da casa, vieram de diversos lugares da cidade de Criciúma e de outros estados brasileiros.

Palavras Chave: Espaço e Lugar; Centro Enraizador; Lugar Essencial; Psicologia Ambiental

\section{ABSTRACT}

This article results from a research about housing issue in a housing complex unit of the "Minha Casa Minha Vida" program in the city of Criciúma/SC. The reflection follows the line of Environmental Psychology, Philosophy and Cultural Geography. The research sample consisted of 54 residents and the objective was to understand the search process for the house through the concept of pilgrimage, identified during the interviews. The research was carried out by the qualitative approach in exploratory and explanatory modalities in the sense of understanding the dynamics of the search for the house itself. The research identified that in the history of people's lives there was a process of pilgrimage and search for the essential place understood as home, marked by great suffering and expectations. It was also observed that this is a new phase of human history, characterized by the specific specificities and possibilities of the time in which we live, at the turn of the century and of the millennium, which leads us to see the World-System through geographic space. From various places in the city of Criciúma and other brazilian states, the pilgrims moved to the housing complex.

Keywords: Space and Place; Center Rooting; Essential Place; Environmental Psychology 
Revista Tecnologia e Ambiente, v. 25, 2019, Criciúma, Santa Catarina/SC ISSN Eletrônico 2358-9426 e ISSN Impresso 1413-8131

\section{INTRODUÇÃO}

O presente artigo trata da discussão dos resultados da pesquisa intitulada "Análise socioambiental de conjuntos habitacionais do programa Minha Casa Minha Vida na cidade de Criciúma - SC”, realizada no período de 2016 a 2018. Essa pesquisa é resultado de discussões do Grupo Interdisciplinar e Interinstitucional de Estudos e Pesquisas sobre Meio Ambiente e Espaço Urbano - GIPMAUR.

A história de Criciúma é marcada pelo exclusivismo da mineração de carvão no período que compreende logo após a Segunda Guerra Mundial até o ano de 1990. O desenvolvimento da cidade trouxe progresso, pois com ela veio a luz elétrica, o trem e o emprego, porém deixou marcas indeléveis no solo, na vegetação e nos rios, que, poluídos, deixaram a população, durante muito tempo, com falta de água potável. A cidade não teve início, o que teve início foi a mineração do carvão que construía, nas bocas das minas, pequenas vilas de operários. Vencida a jazida, ou seja, quando acabava o carvão naquela mina, o empreendedor se deslocava para outro ponto em busca de carvão e construía outra vila. Tanto é que a toponímia da cidade é expressa em muitos bairros pelo nome das minas, como "Mineira Velha", "Mina do Toco", "Mina do Mato", "Mina Brasil”, 'Mina Quatro". Essas pequenas vilas deram origem a bairros e, assim, à cidade, sem um ordenamento territorial e um traçado urbano definido (GONÇALVES; MENDONÇA, 2007). A população atual de Criciúma é de 215.186 habitantes, segundo o IBGE (2019).

Mapa 1: Brasil, Santa Catarina, Criciúma e Quarta Linha

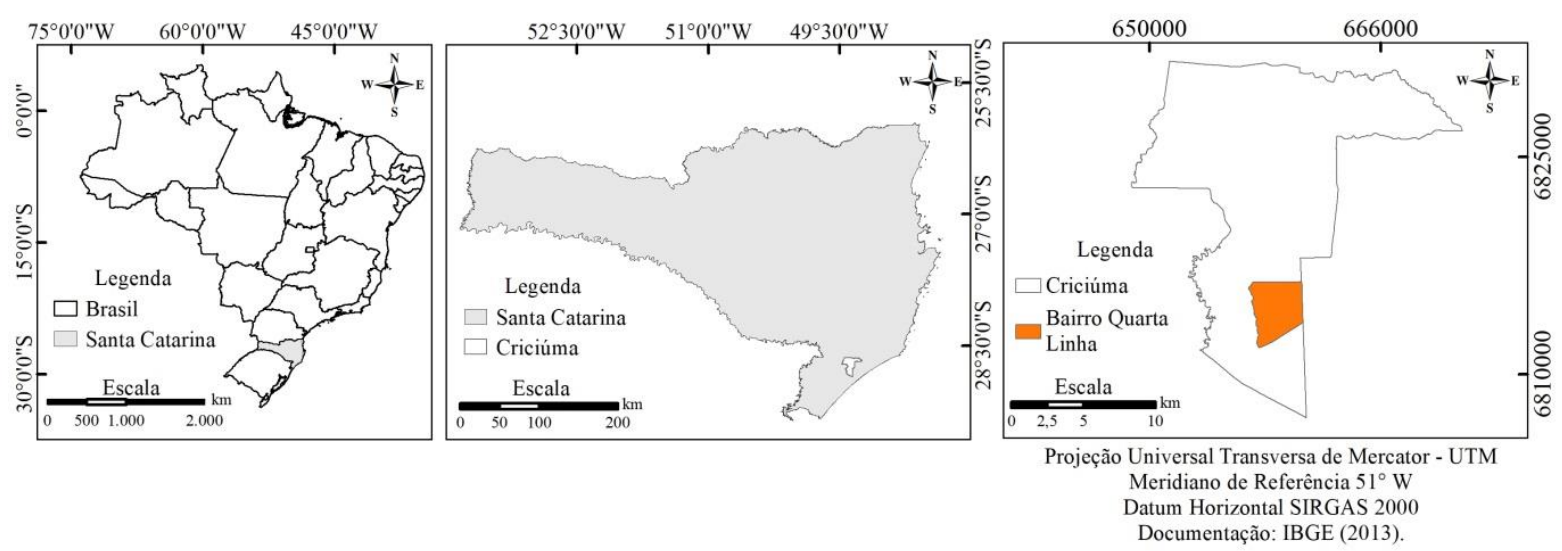

Fonte: Sutil - Laboratório de Planejamento e Gestão Territorial - Unesc (2019).

O conjunto habitacional mencionado possui um total de 24 blocos com 16 apartamentos por bloco, abrigando 384 famílias, num total de 1.152 pessoas. Muitas dessas pessoas peregrinaram por diversas cidades, em alguns, casos países, em busca de um lugar essencial, definido por Gonçalves (2014, p. 89) “como a casa apropriada, o lugar onde o sujeito produz sua subjetividade e constrói sua 
identidade". O contexto no qual essas pessoas se encontram é de extrema vulnerabilidade social, violência e abandono. Convivem em meio ao tráfico de drogas e às constantes invasões da polícia em busca desses traficantes.

Sob esse prisma, o termo peregrinação designa toda trajetória/caminho/esforço efetuada pelos sujeitos desta pesquisa em direção ao alcance de suas casas. Gonçalves (2009) afirma que até mesmo os nômades do deserto, que vivem em gozo de certa liberdade, peregrinando por diversos lugares, vislumbram, em certo momento, a necessidade de aportar por algum tempo e ali construírem o seu abrigo. "Por mais peregrino que seja, há um momento em que o homem precisa de um ancoradouro" (GONÇALVES, 2009, p. 121). As pessoas desta pesquisa, em sua maioria, sempre estiveram em peregrinação, caminhando ao encontro da sobrevivência.

Desse modo, o objetivo deste estudo é entender as nuances do processo de peregrinação em busca da casa, que se dá em um contexto de vida em comunidade por pessoas de diferentes localidades de Criciúma e do país.

\section{METODOLOGIA}

Este estudo deu-se na modalidade de pesquisa qualitativa do tipo exploratória e explicativa, utilizando-se de dados primários, por meio da pesquisa de campo e de dados secundários. A pesquisa foi realizada com 54 moradores do conjunto habitacional.

Segundo Prodanov e Freitas (2013), a abordagem qualitativa destaca a relação dinâmica entre o mundo real e o sujeito, embasando-se em uma fusão entre o mundo objetivo e a subjetividade do sujeito intraduzível numericamente. Do ponto de vista de seus objetivos, destaca-se como uma pesquisa exploratória e explicativa, pois para Knechtel (2014, p. 145):

\footnotetext{
A pesquisa pode ser das seguintes espécies: Exploratória - o pesquisador desenvolve, esclarece e modifica conceitos e ideias com a finalidade de formular problemas mais precisos e hipóteses pesquisáveis para estudos posteriores. Geralmente, envolve o levantamento bibliográfico e documental [...] Explicativa - o pesquisador busca a identificação de fatores que determinam ou contribuem para a ocorrência dos fenômenos; busca explicar a razão e o porquê deles.
}

A análise dos dados foi norteada na articulação entre os dados coletados e o referencial teórico da Psicologia Ambiental, da Filosofia e da Geografia Cultural. A motivação para estudar a peregrinação veio de um dos objetivos do projeto de pesquisa, que era identificar os sentimentos das pessoas que vivem no conjunto habitacional.

Para o levantamento bibliográfico, foram utilizados artigos pesquisados na base de dados SciELO, por meio dos seguintes descritores: "peregrinação" e "busca da casa". Também, livros 
pertencentes ao próprio laboratório de pesquisa e da Biblioteca da Universidade do Extremo Sul Catarinense - Unesc.

Dos dados da pesquisa, utilizaram-se somente aqueles que são referentes ao processo de peregrinação das pessoas. Vale frisar que todos os procedimentos éticos foram obedecidos segundo a Resolução nº 196, de 10 de outubro de 1996, expedida pelo Ministério da Saúde, que regulamenta os preceitos éticos a serem seguidos pelas pesquisas com humanos. Os comitês de ética de todos os centros de pesquisa devem seguir essa resolução e, assim, foi com o Comitê de Ética da Universidade do Extremo Sul Catarinense. Todos os projetos de pesquisa devem ser submetidos à Plataforma Brasil, seguindo esses preceitos. A apresentação da proposta da pesquisa e a assinatura dos termos de compromisso foi assegurada a todos. Junto a isso, o direito do sigilo, privacidade e a recusa de participação a qualquer momento foi garantido, obedecendo às normas observadas pelo Comitê de Ética em Pesquisa da Unesc, designadas pela aprovação do projeto de pesquisa.

\section{RESULTADOS E DISCUSSÃO}

O ser humano está sempre em busca de seu lugar; os caminhantes antigos, os nômades do deserto, os andarilhos, os moradores de rua, ou, ainda, a raça humana, sem distinção de classe ou cor, todos almejam por uma casa que vá além do corpo. Nas palavras de Gonçalves (2014, p. 87), isso vai além de ter um teto:

Uma proteção ao corpo, nunca se preocupando com as outras necessidades humanas ligadas a casa como memória e convívio, lugar identificador e enraizador onde se produz a subjetividade. A casa como lugar de amparo, de conforto, de proteção e de segurança, como preconiza a Psicologia Ambiental.

Valadares (2000) insiste no fato de que o homem nunca abandona a busca de seu lugar. "Ressaltarei, apenas que essa busca é sempre um fazer, uma ação singular, sempre transformadora do ambiente dito natural. Há um modelo de alegria, de prazer, um paraíso perdido, descrito não somente pela psicanálise mas, também pelas ciências da história e, sobretudo, pela história da arte" (VALADARES, 2000, p. 86).

Bachelard (1989) traz que, para um estudo fenomenológico dos valores de intimidade do espaço interior, a casa é, evidentemente, um ser privilegiado, desde que a consideremos, ao mesmo tempo, uma unidade em sua complexidade. A busca do lugar essencial de que fala Gonçalves (2014) é referenciada em Heidegger (2003). O autor coloca que sempre estamos em busca do nosso lugar essencial no mundo e esse lugar ancorado no espaço é a casa. A casa é, objetivamente, um lugar 
protetor e, ao mesmo tempo, integrador de subjetividades que nela habitam, é o lugar de convívio e de amparo, que, segundo Valadares (2000), nos remete à simbologia do útero materno, onde nos sentiríamos seguros, protegidos.

Esse imaginário de casa dificilmente é considerado pelos programas oficiais de moradia adotados pelos governos, como esse no qual se aporta nossa pesquisa. Prosseguindo com Bachelard (1989), "a casa é o nosso canto do mundo, nossa vida adulta é tão despojada nos primeiros bens, os vínculos antropocósmicos são tão frouxos que nem sentimos sua primeira ligação com o universo". A casa nos liga a esse cosmos do qual fazemos parte, mas estamos inertes à sua presença. Nossa imaginação trabalha nesse sentido de encontrar o melhor abrigo: "aí veremos a imaginação construir paredes, com sombras impalpáveis, reconfortar-se com ilusões de proteção, ou inversamente, tremer atrás de grossos muros, duvidar das mais sólidas muralhas. Vive a casa em sua realidade e em sua virtualidade, através do pensamento e dos sonhos” (BACHELARD, 1989, p. 25).

Leitão (2007) fala da casa como um tumulto de recordações. A temática da casa como devaneio de pertencimento ganhará contornos mais nítidos. Zygmundt Bauman (2009, p. 21) diz: “os devaneios de pertencer a uma casa expressam os dinamismos de uma imaginação em que teima em ludibriar, em se contrapor as duras armadilhas de um processo civilizatório que tem por objetivo maior, uma única visão de mundo concebida como verdade absoluta”.

Essa verdade absoluta, para Bauman (2009), nos remete à sua obra de 2017 "Estranhos à nossa porta", que fala dos refugiados de guerra à deriva em barcos em alto mar, que deixaram suas casas, mas que, desesperada e avidamente, pois sua vida estava em risco, buscam esse lugar imaginado que lhes dê um novo pertencimento e uma possibilidade de amparo e abrigo. Essa peregrinação como uma dinâmica do mundo atual, globalizado e desigual, põe a questão da casa, da moradia, como um dos direitos mais básicos e fundamentais do ser humano no mundo atual. Assolados por desastres naturais, preveníveis e outros, inerentes à dinâmica da Terra, vimos abrigos temporários, desabrigados, moradores de rua e a eterna peregrinação em busca do lugar essencial, como diz Heidegger (2003).

Os sujeitos vivenciam o mundo ao seu redor por meio dos sentidos, tais como olfato, tato, paladar, audição e visão. Todos esses nos permitem entrar em contatos com sensações, ter impressões e sentir aquilo à nossa volta.

Como exemplo disso, temos a criança, que, conforme vai desenvolvendo seus órgãos sensoriais, seus sentidos, vai, aos poucos, se apegando a objetos, a lugares, a pessoas importantes e, por último, a localidades. Nesse sentido, a mãe pode ser definida, entendendo lugar como centro de valores, como o primeiro lugar da criança, um lugar de alimento e apoio (TUAN, 1983). 
Yi-fu Tuan (1983, p. 37) nos traz que "o lugar pode adquirir profundo significado para o adulto por meio do contínuo acréscimo de sentimento ao longo dos anos. Cada peça de móveis herdados, ou mesmo uma mancha na parede, conta uma história".

O lugar é o local privilegiado para o surgimento do sujeito. Por sua vez, os lugares são locais do espaço. Mas espaço é diferente de lugar, no sentido de que, nos lugares, o sujeito efetiva o processo de significação. Nos lugares, ele mora, trabalha, caminha, passeia e relaciona-se. Com o corpo, mente e sentimento, o indivíduo se torna sujeito. De corpo inteiro e alma atenta, ele se apropria do espaço que sente, observa e vê (GONÇALVES, 2009).

Nesse sentido, o espaço representa uma necessidade biológica, psicológica, social e um atributo espiritual. Também está diretamente relacionado à liberdade, sendo considerado por muitos o símbolo dessa. E, assim, se diferencia o espaço e o lugar; o espaço aberto sugere futuro e convida à ação. $\mathrm{O}$ espaço fechado e humanizado é lugar, sendo esse um centro de valores estabelecidos (TUAN, 1983).

Essa argumentação nos faz pensar toda uma vida de sofrimento vivida por essas pessoas que procuraram o conjunto habitacional, locus da nossa pesquisa, como a casa essencial inspirada no lugar essencial de Heidegger (2003). Gonçalves (2014), em seu trabalho Habitar: a casa como contingência da condição humana, fala da casa biológica e da casa simbólica. Pela entrevista dos 54 moradores, percebeu-se que esses não queriam somente uma casa biológica, mas uma casa simbólica, na qual pudessem finalmente sentirem-se protegidos, abrigados e onde pudessem construir seus sonhos. Se a casa biológica ainda é um resquício da casa que abrigava o corpo do trabalhador inglês da Revolução Industrial no final do Século XVIII, que tinha por objetivo somente preservar seu corpo enquanto força de trabalho, a casa simbólica representa a possibilidade de preservar a integridade da subjetividade humana, enraizando-a no cosmos que se concretiza nos espaços, tanto geográficos como culturais. A cidade é o espaço onde se congrega um maior número de casas. No apenhamento de tantos seres humanos que se aproximam para buscar e viabilizar seus sonhos com as possibilidades que a cidade oferece, a casa é o único lugar íntimo onde se poderá, sem atribulações, construir seus devaneios e sonhos de uma vida melhor.

Constatamos que os programas habitacionais para a população de baixa renda no Brasil ainda permanecem com essa visão de que a casa para o pobre pode ter de 32 a 42 metros quadrados. Sempre alegando falta de recursos para construções maiores, os governos brasileiros desde o Banco Nacional da Habitação, criado em 21 de agosto de 1964 por meio da Lei n ${ }^{\circ}$ 4.380, até os dias de hoje, concebem a moradia popular na concepção de casa biológica. Então, contrapondo toda argumentação teórica deste artigo, a casa enquanto lugar enraizador, memória e convívio, remissão ao útero materno, não é identificada no âmbito do conjunto habitacional estudado. 
Segundo Rolnik et al. (2015), o lançamento do Programa Minha Casa Minha Vida foi, também, na perspectiva de minimizar a crise internacional da economia em 2008, com reflexos também no Brasil, de aquecer o mercado de trabalho com a implementação da construção civil, dessa forma, aquecendo a economia. A segregação sócio-espacial é uma recorrência dessa falta de planejamento inclusivo, por meio do qual a população pudesse opinar como fazem em alguns países da América Latina. Podemos citar o caso chileno, em que o arquiteto Alejandro Aravena ganhou o prêmio Pritzker, em 2016, por seu trabalho em um programa de habitação social. Quando lhe foi pedido para construir alojamentos para cem famílias, Aravena procurou inspiração fora do comum: a sabedoria das favelas e dos bairros de lata. Enfrentou um problema complexo, mas com soluções simples: passou muito tempo convivendo na favela, conversando com seus habitantes. Perguntado sobre o seu método de trabalho, respondeu: "mi filosofía arquitectónica? Incluir a la comunidade em el processo" (ARAVENA, 2014). O que surpreende o pesquisador das Ciências Sociais é que a população não participou efetivamente do planejamento desses conjuntos habitacionais e nem da escolha do local onde eles seriam construídos, mas a lógica explicita, segundo Rolnik et al. (2015), que o Programa veio para aquecer a economia. Para isso, precisaria somente da intervenção do agente financeiro, a Caixa Econômica Federal, e do mercado, os agentes do capital imobiliário.

Segundo os dados coletados durante a pesquisa, foi identificado que 46 dos entrevistados tiveram como sua última cidade de procedência a própria Criciúma (Figura 1). Entende-se como última procedência o último local que os sujeitos habitaram antes de se dirigirem ao condomínio habitacional.

Desses, dois vieram do bairro Próspera, quatro do Pinheirinho, três do Santa Luzia, um do Mina União, um do Mina Brasil, dois do Mina do Mato, um do Morro Estevão, um do Cristo Redentor, um do Vila Zuleima, dois do Vila Manaus, um do Morro Grande, um do São Luiz, um do São Marcos, dois do São Francisco, um do Universitário, um do Bairro Brasília, um do Rio Maina, um do Renascer, um do Centro, um do Operária Nova, um do Jardim União, um do Minera Nova e outros 15 não identificaram o bairro.

Com relação a outras cidades de última procedência, obteve-se: um da cidade Barreira, um de Morro da Fumaça, um de Içara, um de Imaruí, um de Balneário Camboriú, um de Tubarão, um de Londrina/PR, um de São Paulo/SP e um não identificou sua última procedência (Figura 1).

Também foram coletados dados que se referem a locais habitados antes de chegarem à sua última procedência, espacializados na Figura 2. Esses locais são de cidades do próprio estado de Santa Catarina, como Florianópolis, Tubarão, Concórdia, Xanxerê, Imbituba, Joinville, Laguna, Içara, Siderópolis, Treviso, Cocal do Sul, Sombrio, Jacinto Machado, Braço do Norte, Nova Veneza, Forquilhinha, Lages e Jaguaruna. 
Revista Tecnologia e Ambiente, v. 25, 2019, Criciúma, Santa Catarina/SC ISSN Eletrônico 2358-9426 e ISSN Impresso 1413-8131

Também foram identificados locais de outros estados, como Porto Alegre/RS, Tramandaí/RS, Livramento/RS, Itaqui/RS, Porto Xavier/RS, São Paulo/SP, Curitiba/PR, Brasília/DF, Cuiabá/MT, João Pessoa/PB, Rio Bonito/RJ, Rio de Janeiro/RJ, Santa Luz/BA, Salvador/BA e Amazonas/AM. Além de outros estados, também há dados de outros países, como exemplo, de Portugal.

Figura 1: Locais de Última Procedência
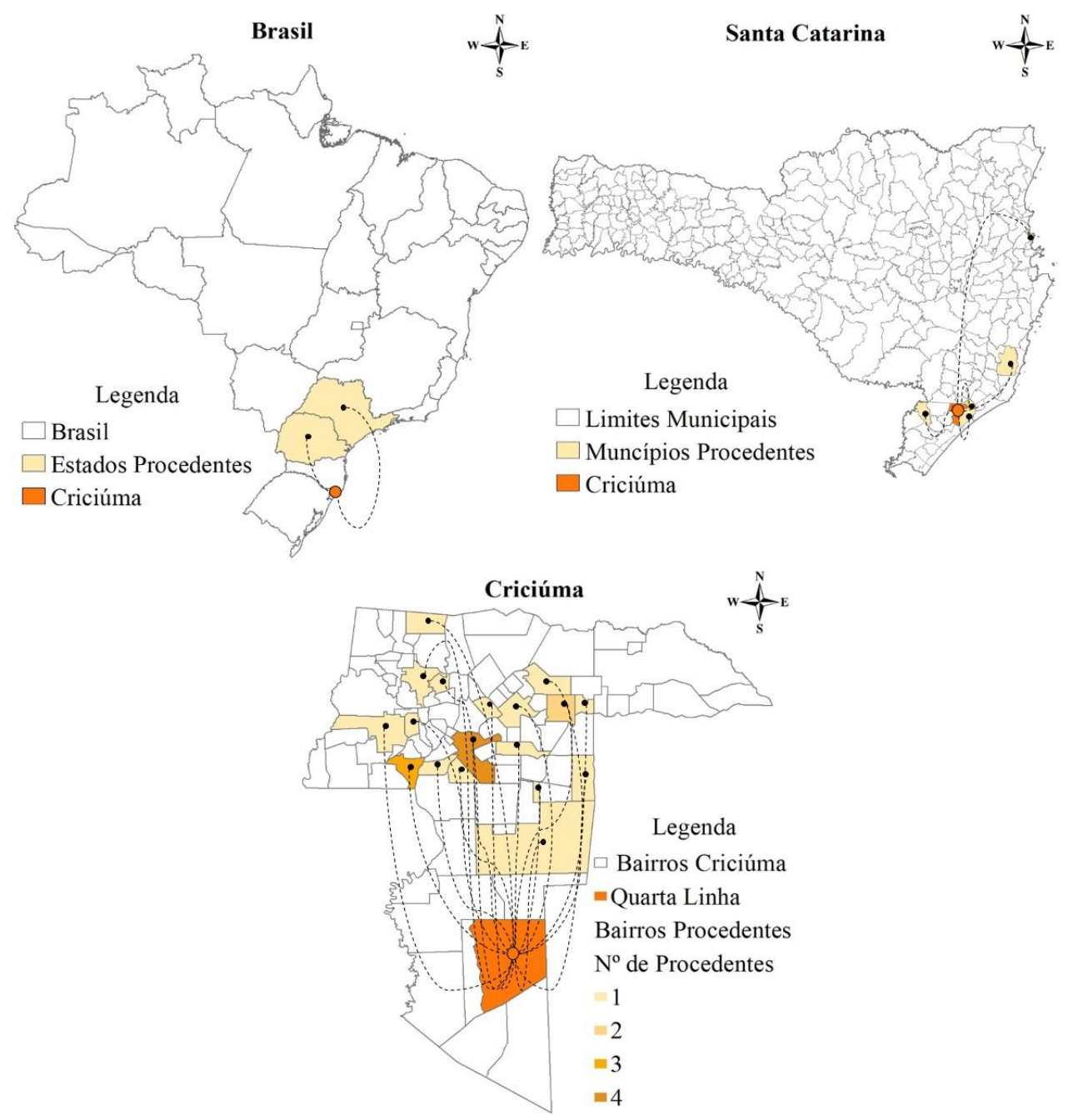

Fonte: Sutil - Laboratório de Planejamento e Gestão Territorial - Unesc (2019).

Figura 2: Locais Anteriores à Última Procedência 


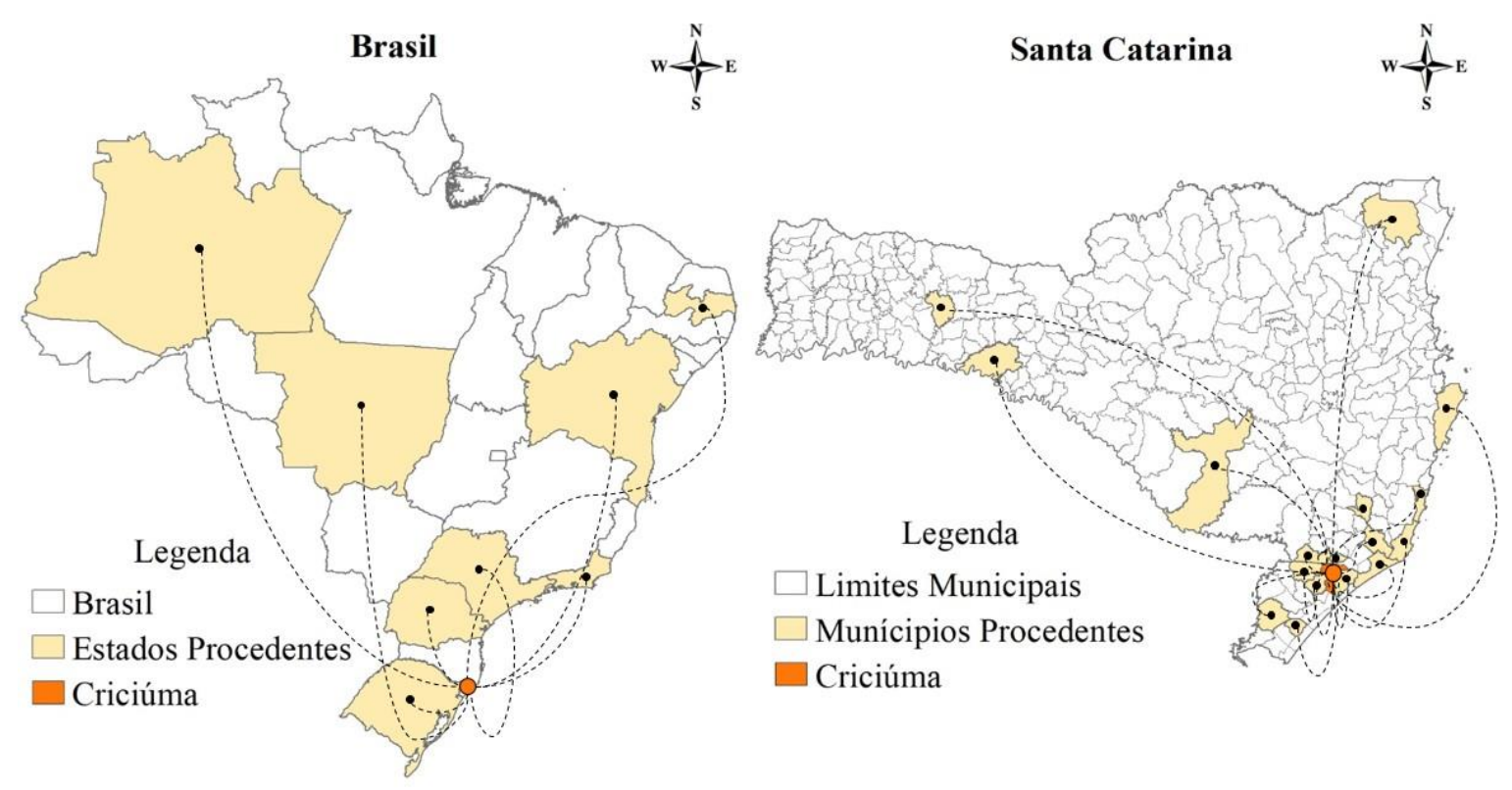

Fonte: Sutil - Laboratório de Planejamento e Gestão Territorial - Unesc (2019).

\section{CONSIDERAÇÕES FINAIS}

A pesquisa mostrou a segregação socioespacial do conjunto habitacional estudado que, segundo Marques e Rodrigues (2013). Cercado por um muro alto, o conjunto habitacional foi implantado em uma área semi-rural, onde plantações são cultivadas e animais pastejam ao seu redor, por isso distante dos serviços básicos como transporte, escola e serviços de saúde.

A produção capitalista do espaço, segundo Harvey (2005), faz o ajuste espacial, ou seja, cada qual no seu lugar, na lógica capitalista. Os melhores terrenos vão ficar próximos de todos os serviços urbanos. Os mais precários, ou até em locais de risco, são destinados à população de baixa renda. Exemplos emblemáticos, em Criciúma, são os bairros Cristo Redentor, implantado sobre terreno com descenso de solo, e o bairro Renascer, implantado sobre o antigo lixão da cidade.

Outro importante aspecto observado foi que grande parte da população está em condição de trabalho precarizado, ou seja, trabalho informal sem a garantia de direitos. Mas a situação mais agravante foi a falta de um programa por parte da Prefeitura que ensinasse o viver em coletividade. O condomínio é administrado por uma empresa, cujo o síndico não mora no conjunto e as pessoas ficam "a Deus dará", cada família vivendo sua vida isolada em seus pequenos apartamentos. Grande número de crianças sozinhas em seus apartamentos em plena tarde foram encontradas durante o desenvolvimento da pesquisa, assim como idosos abandonados por sua família, sendo portadores de necessidades especiais, como, por exemplo, uma senhora cadeirante que morava sozinha.

Porém, o que mais chamou atenção da equipe de pesquisa foi a tristeza estampada no rosto dos entrevistados que passivamente respondiam às perguntas dos pesquisadores, mas não expressaram alegria de ali construir um projeto de vida. Portanto, a casa simbólica tão necessária para a construção da subjetividade humana, não foi localizada na amostra da pesquisa. Junto a isso, tem- 
se a frustação de um sonho que não se realizou, a promessa de uma casa própria que, ao invés de remeter a um lugar seguro e propício para o desenvolvimento humano, se insere em meio à violência e ao distanciamento da cidade.

O lugar onde moramos estabelece nossa identidade à medida que define nosso endereço. A partir da Psicologia, podemos ver o quanto é constrangedora e insegura a situação de um sujeito não ter um endereço, ou de tê-lo em um local discriminado, situado em áreas violentas ou às margens da cidade. A Psicologia Ambiental busca compreender como as espacialidades são construídas e o quanto podem influenciar na produção da subjetividade e no comportamento humano.

\section{REFERÊNCIAS}

ARAVENA, A. Mi Filosofía Arquitectónica? Incluir a la comunidade em el proceso. Realização de TedGlobal. Rio de Janeiro: Ted, 2014. (14 min.), 2014. Disponível em: <https://www.ted.com/talks/alejandro_aravena_my_architectural_philosophy_bring_the_communit y_into_the_process?language=es>. Acesso em: 27 set. 2019.

BACHELARD, G. A poética do espaço. São Paulo: Martins Fontes, 1989.

BAUMAN, Z. Confiança e Medo na Cidade. Rio de Janeiro: Zahar, 2009.

BAUMAN, Z. Estranhos à nossa porta. Rio de Janeiro: Zahar, 2017.

BRASIL. Conselho Nacional de Saúde. Resolução $\mathbf{n}^{\mathbf{0}}$ 196, de 10 de outubro de 1996. Aprova normas regulamentadoras de pesquisas envolvendo seres humanos. Brasília, DF: Diário Oficial da União, 1996.

BRASIL. Presidência da República. Lei $\mathbf{n}^{0}$ 4.380, de 21 de agosto de 1964. Institui a correção monetária nos contratos imobiliários de interêsse social, o sistema financeiro para aquisição da casa própria, cria o Banco Nacional da Habitação (BNH), e Sociedades de Crédito Imobiliário, as Letras Imobiliárias, o Serviço Federal de Habitação e Urbanismo e dá outras providências. Brasília, DF: Diário Oficial da União, 1964.

GONÇALVES, T. M.; MENDONÇA, F. A. Impactos, Riscos e Vulnerabilidade Sociomabientais da Produção do Carvão em Criciúma/SC (Brasil). Curitiba: Ra'E GA, n. 14, p. 55-65, 2007.

GONCALVES, T. M. Habitação e sustentabilidade urbana. Revista INVI, Santiago, v. 24, n. 65, p. 113-136, mayo 2009. Disponível em: http://bit.ly/2YUOXeX. Acesso em: 8 jul. 2019.

GONÇALVES, T. M. Habitar: a casa como contingência da condição humana. Revista INVI, Santiago, v. 29, n. 80, p. 83-108, mayo 2014. Disponível em: http://bit.ly/2Y3fUj7. Acesso em: 8 jul. 2019.

HARVEY, D. A produção capitalista do espaço. São Paulo: Annablume, 2005.

HEIDEGGER, M. A caminho da linguagem. Petrópolis: Vozes, 2003.

IBGE. População Estimada Para 2019. IBGE, 2019.

KNECHTEL, M. R. Metodologia da pesquisa em educação: uma abordagem teórico-prática dialogada. Curitiba: Intersaberes, 2014.

LEITÃO, L. Entra na tua casa: anotações sobre arquitetura, espaço e subjetividade. In: LEITÃO, L.; AMORIM, L. (eds.). A casa nossa de cada dia. Recife: Universitária da UFPE, 2007.

MARQUES, E; RODRIGUES, L. O Programa Minha Casa Minha Vida na metrópole paulistana: atendimento habitacional e padrões de segregação. Recife: Revista Brasileira de Estudos Urbanos e Regionais. v. 15, 2013.

PRODANOV, C. C.; FREITAS, E. C. Metodologia do trabalho científico: métodos e técnicas de pesquisa e do trabalho acadêmico. 2. ed. Novo Hamburgo: FEEVALE, 2013. 
ROLNIK, R. et al. O programa Minha Casa Minha Vidada nas regiões metropolitanas de São Paulo e Campinas: aspectos socioespaciais e segregação. São Paulo: Cadernos Metrópole, v. 17, n. 33, 2015.

SUTIL. Laboratório de Planejamento e Gestão Territorial. Criciúma: UNESC, 2019.

TUAN, Yi-Fu. Espaço e Lugar: a perspectiva da experiência. São Paulo: DIFEL, 1983.

VALADARES, J. C. Qualidade do espaço e da habitação humana. Ciência \& Saúde Coletiva. v. 5, n. 1, 2000. Disponível em: http://bit.ly/2XG1FkW. Acesso em: 8 jul. 2019. 